\title{
Surgery for type A intramural hematoma: a systematic review of clinical outcomes
}

\author{
David H. Tian ${ }^{1,2}$, Adam Chakos $^{1}$, Lucy Hirst ${ }^{1}$, Sally T. W. Chung ${ }^{1}$, Tristan D. Yan ${ }^{1,3}$ \\ ${ }^{1}$ Collaborative Research (CORE) Group, Macquarie University, Sydney, Australia; ${ }^{2}$ Department of Anaesthesia and Perioperative Medicine, \\ Westmead Hospital, Sydney, Australia; ${ }^{3}$ Department of Cardiothoracic Surgery, Royal Prince Alfred Hospital, Sydney, Australia \\ Correspondence to: David H. Tian. Collaborative Research (CORE) Group, Macquarie University, Balaclava Rd, Macquarie Park, NSW 2109, \\ Australia. Email: drdavidtian@gmail.com.
}

\begin{abstract}
Background: Management of type A intramural hematoma (IMH) remains controversial, with opinions divided as to whether patients should be treated with early aggressive surgery or a more conservative approach. The present systematic review aims to evaluate the mortality and morbidities following surgery for type A IMH.

Methods: Electronic searches were performed on five databases from dates of inception to December 2018. All studies with surgical outcomes for type A intramural hematoma were identified by two independent researchers and relevant data extracted. Random-effects meta-analysis of proportions or meta-analysis of means were performed to aggregate the data. Survival data were pooled using reconstructed individual patient data derived from Kaplan-Meier curves.

Results: Fifteen studies with 744 patients were identified. Ten studies were from Asian countries $(73 \%$ of patients). Overall mortality was 8.2\% [95\% confidence interval (CI): 4.6-13.9\%]. Mortality from Asian centers was 5.3\% (95\% CI: 3.6-7.7\%) and 18.9\% (95\% CI: 7.0-40.4\%) in Western centers. Postoperative complications were poorly reported and hence not analyzable. Overall pooled survival of 343 patients from four studies at 1-, 2-, 3-, 5-, and 10-year was 91.8\%, 90.2\%, 89.2\%, 87.7\%, and 71.1\%, respectively.

Conclusions: There is an acceptable level of risk of death after surgery for type A IMH, though significant variations exist between results from Asian and Western centers. More detailed studies are required to clarify the controversies surrounding management of type A IMH.
\end{abstract}

Keywords: Type A intramural hematoma; systematic review; clinical outcomes

Submitted Aug 15, 2019. Accepted for publication Aug 19, 2019.

doi: $10.21037 /$ acs.2019.08.07

View this article at: http://dx.doi.org/10.21037/acs.2019.08.07

\section{Introduction}

Intramural hematoma (IMH) is a pathological variant of acute aortic syndrome, classically described as a hematoma within the aortic media without communication to the true aortic lumen. However, despite its similarities to aortic dissection, much controversy exists as to the management of IMH, particularly for lesions that involve the ascending aorta (1). Classified as type A IMH, these lesions can have a high propensity to progress to aortic rupture or aortic dissection (2), therefore leading some to advocate for early surgery, similar to acute type A dissections. The present systematic review aims to evaluate the mortality and morbidities following surgery for type A IMH.

\section{Methods}

\section{Literature search}

Electronic searches were performed on Medline, Embase, PubMed, Scopus, and Cochrane Database of Systematic Reviews, from database dates of inception to December 2018. Studies that presented data on surgical outcomes of acute type A IMH management were identified. The search terms ('intramural hematoma' or 'IMH' or 'intramural hemorrhage' or 'aortic hematoma') were used either as 
key terms or MeSH headings. All identified records were evaluated by two independent researchers (DH Tian and A Chakos) according to the inclusion/exclusion criteria. Conflicts were resolved by the senior researcher (DH Tian). Reference lists of the included studies were also reviewed for additional relevant studies.

\section{Inclusion/exclusion criteria}

Eligible studies for the present review included any studies that included at least 10 patients who had acute type A intramural hematoma and received surgical treatment within the initial admission. Studies that did not present primary outcomes were excluded. All publications were limited to the English language. Letters, editorials, database registrations, and review articles were excluded.

\section{Outcomes of interest}

The primary outcome was mortality (either 30-day or in-hospital). Secondary outcomes included stroke, renal failure, bleeding, and hospital lengths of stay. All data were extracted independently from abstracts, texts, figures, and tables by two independent researchers (L Hirst and STW Chung) into Microsoft Excel. Discrepancies between the two researchers were resolved by the senior researcher (DH Tian). The quality of the studies was assessed using a modified schema used for assessing case series, developed by the Institute of Health Economics (Alberta, Canada) (3) (Table S1). This checklist examines the suitability of study objective(s), design, population, intervention, outcome measure, statistical analysis, appropriateness of results and conclusions, and competing interests.

\section{Statistical analysis}

Descriptive statistics were calculated for all collected variables. Categorical or continuous variables were aggregated using random-effects meta-analysis of proportions or means, as appropriate. Data are presented as $\mathrm{N}(\%)$ with $95 \%$ confidence intervals or mean \pm standard deviation (SD). Data that were presented as median and interquartile ranges were converted into mean $\pm \mathrm{SD}$ using the methods of Wan and colleagues (4). Survival curves were aggregated using the method of Guyot and colleagues, which reconstructs individual patient data from digitized Kaplan-Meier curves using an iterative algorithm (5). All statistical analyses were performed in $\mathrm{R}$ (version 3.5.2, $\mathrm{R}$
Foundation for Statistical Computing, Vienna, Austria).

\section{Results}

\section{Literature search}

Overall, 5,133 unique records were identified from the literature search (Table 1). Following review, 15 were included in the quantitative analysis (6-20), with a total of 744 patients. Four were multi-center studies $(7,15,17,20)$, including an international registry (7). The median size of the included studies was 25 patients (interquartile range 16-53). All were retrospective analyses of prospectively or retrospectively collected data. Ten of fifteen studies, including $73 \%$ of patients, were from Asian centers.

The quality of the studies was varied. Two studies were deemed high-quality, nine as medium-quality, and four as low-quality studies. Nearly half of all studies did not identify whether patient recruitment was consecutive. Adverse events were reported by less than half of all studies.

Overall mortality was $8.2 \%$ [95\% confidence interval (CI): 4.6-13.9\%; $\mathrm{I}^{2}=69 \%$ ]. Meta-regression with region of study (Western vs. Eastern countries) found that this alone accounted for $62 \%$ of the identified heterogeneity $(\mathrm{P}<0.001)$. Indeed, further subgroup analysis found pooled mortality of $18.9 \%$ in Western studies (95\% CI: 7.4-40.4\%, $\mathrm{I}^{2}=77 \%$ ), compared to $5.3 \%$ in Eastern studies (95\% CI: $\left.3.6-7.7 \%, \mathrm{I}^{2}=0 \%\right)$.

Permanent neurological deficit was only reported in five studies, with an incidence of 7.6\% (95\% CI: 4.2-13.2\%; $\left.\mathrm{I}^{2}=52 \%\right)$. Remaining outcomes were poorly reported and were not able to be aggregated.

Four studies presented survival data for 342 patients undergoing urgent surgery $(9,10,12,16)$. Pooled overall survival at 1-, 2-, 3-, 5-, and 10-year was $91.8 \%, 90.2 \%$, $89.2 \%, 87.7 \%$, and $71.1 \%$, respectively (Figure 1 ).

\section{Discussion}

The management of type A intramural hematoma remains controversial. Some studies recommend early surgery for these patients due to poor prognosis with medical management (21), while others have demonstrated acceptable outcomes with medical therapy alone and timely operation (10). Indeed, progression to aortic rupture or aortic dissection occurs in up to $45 \%$ of patients with ascending aortic IMH (20), with the proximal location of IMH considered an independent predictor of complications 


\begin{tabular}{|c|c|c|c|c|c|c|c|c|}
\hline Study & $\begin{array}{l}\text { Publication } \\
\text { year }\end{array}$ & Institution & Country & $\begin{array}{l}\text { Study } \\
\text { period }\end{array}$ & Study type & Patients & Mortality & Stroke \\
\hline Choi (6) & 2014 & $\begin{array}{l}\text { Yeungham University } \\
\text { Medical Center, } \\
\text { Gyeongsan }\end{array}$ & South Korea & 2000-2010 & Retrospective & 17 & 1 & NR \\
\hline Evangelista (7) & 2005 & $\begin{array}{l}\text { International Registry for } \\
\text { Aortic Dissection }\end{array}$ & International & $1996-2001$ & Retrospective & 14 & 6 & NR \\
\hline Ferrera (8) & 2017 & $\begin{array}{l}\text { Hospital Clinico San } \\
\text { Carlos, Madrid }\end{array}$ & Spain & 2000-2015 & Retrospective & 16 & 7 & 1 \\
\hline Hata (9) & 2014 & $\begin{array}{l}\text { Nihon University School } \\
\text { of Medicine, Tokyo }\end{array}$ & Japan & 1998-2012 & Retrospective & 112 & 6 & 4 \\
\hline Kitai (10) & 2009 & $\begin{array}{l}\text { Kobe City Medical Center } \\
\text { General Hospital, Kobe }\end{array}$ & Japan & 1986-2006 & Retrospective & 32 & 1 & 4 \\
\hline Liu (11) & 2018 & $\begin{array}{l}\text { Shanghai Ninth People's } \\
\text { Hospital, Shanghai }\end{array}$ & China & 2014-2017 & Retrospective & 11 & 0 & NR \\
\hline Matsushita (12) & 2016 & $\begin{array}{l}\text { Sakakibara Heart } \\
\text { Institute, Tokyo }\end{array}$ & Japan & 2000-2011 & Retrospective & 121 & 1 & 6 \\
\hline Moizumi (13) & 2004 & $\begin{array}{l}\text { Sendai City Medical } \\
\text { Center, Sendai }\end{array}$ & Japan & 1990-2002 & Retrospective & 20 & 2 & NR \\
\hline Nakamura (14) & 2006 & $\begin{array}{l}\text { University of Miyazaki, } \\
\text { Miyazaki, }\end{array}$ & Japan & 1993-2004 & Retrospective & 22 & 0 & NR \\
\hline Park (15) & 2008 & $\begin{array}{l}\text { Seoul National University } \\
\text { Bundang Hospital, Seoul }\end{array}$ & South Korea & $1997-2007$ & Retrospective & 37 & 2 & NR \\
\hline Sandhu (16) & 2016 & $\begin{array}{l}\text { Memorial Hermann } \\
\text { Hospital, Houston }\end{array}$ & United States & 1999-2014 & Retrospective & 101 & 12 & 13 \\
\hline Schoenhoff (17) & 2017 & $\begin{array}{l}\text { University Hospital } \\
\text { Berne, Berne }\end{array}$ & Switzerland & $1999-2013$ & Retrospective & 16 & 0 & NR \\
\hline Song (18) & 2009 & $\begin{array}{l}\text { Asan Medical Center, } \\
\text { Seoul }\end{array}$ & South Korea & $1993-2008$ & Retrospective & 33 & 2 & NR \\
\hline Uchida (19) & 2013 & $\begin{array}{l}\text { Yokohama City University } \\
\text { Hospital, Yokohama }\end{array}$ & Japan & 1994-2012 & Retrospective & 165 & 10 & NR \\
\hline $\begin{array}{l}\text { von Kodolitsch } \\
\text { (20) }\end{array}$ & 2003 & $\begin{array}{l}\text { University Hospital } \\
\text { Rostock, Rostock; } \\
\text { University Hospital } \\
\text { Eppendorf, Hamburg; } \\
\text { Hannover Medical } \\
\text { School, Hannover; } \\
\text { Christian-Albrechts- } \\
\text { University, Kiel; University } \\
\text { of Bologna, Bologna }\end{array}$ & Germany/Italy & $1994-2000$ & Retrospective & 27 & 2 & NR \\
\hline
\end{tabular}

NR, not reported. 


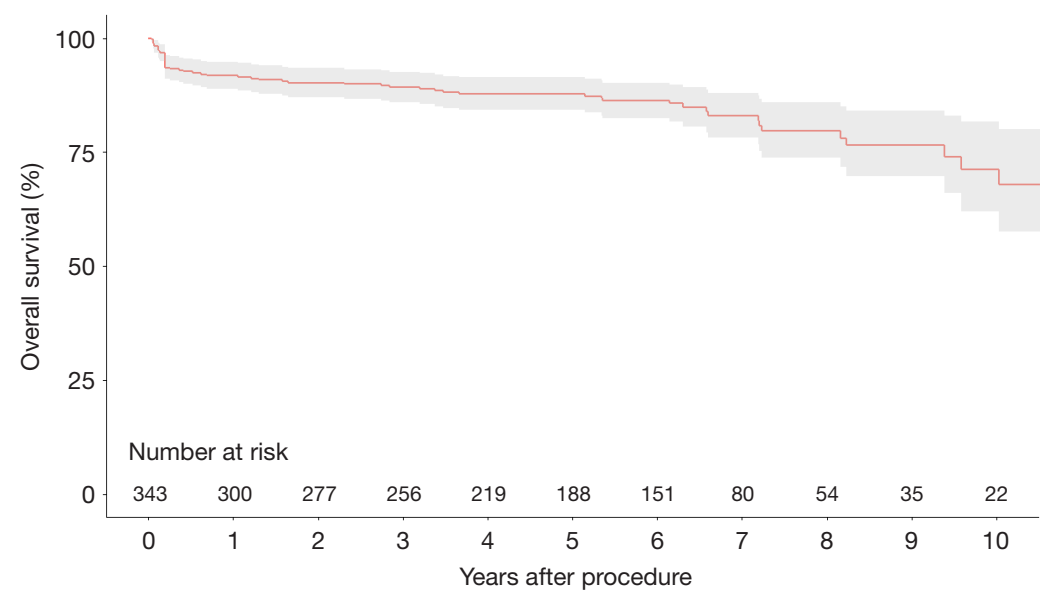

Figure 1 Overall survival after surgery for type A intramural hematoma. Data aggregated from four studies using methods of Guyot and colleagues (5).

in numerous studies $(2,7,22)$. In the present analysis, surgical mortality for type A IMH was $8.2 \%$, arguably lower than the risks of medical management $(20,21)$.

The evidence for management of IMH remains conflicted, with disparate findings across regions. While most Western institutions advocate urgent surgery for type A IMH, some Asian centers have shown acceptable outcomes with medical management and delayed surgery $(10,16)$. While Western guidelines recognize IMH to be a subset of acute aortic syndrome, some Asian societies consider IMH to be a distinct pathological process that requires unique consideration of treatment (23). Indeed, the 2010 American College of Cardiology Foundation and the American Heart Association (ACCF/AHA) guideline and 2014 European Society of Cardiology guideline both recommend urgent surgery $(24,25)$ (Class IC recommendation), whereas the 2011 Japanese Circulation Society recommends medical therapy (Class IC recommendation) for type A IMH (26). In the present study, the mortality for Western institutions was $18.9 \%$, compared to $5.3 \%$ for Eastern centers, although significant heterogeneity between the Western studies existed. Two Western studies contributed the majority of surgical mortality; a Spanish single-institutional series reported seven deaths from 16 operations (four intraoperative deaths, two deaths from hypoxic encephalopathy, and one from stroke) (8), while six deaths were reported from 14 operations in the IRAD series (7). The lack of information and heterogeneity regarding patient comorbidities, presentation and patient selection, surgical approach, and extent of surgery precludes recommendations based on these results.

The timing of surgical intervention for type A IMH is of significant interest to clinicians. In a study of 101 patients with type A IMH by Sandhu and associates in Houston, USA, the median time to surgery was 55 hours, with only a small proportion of patients undergoing emergent surgery (16). This is in concordance with other reports suggesting that deferring non-emergent surgeries may be advantageous, particularly as it may allow time for the aortic wall to thicken and the intimal flap to stabilize $(6,10,16,27)$. However, the risk of rupture during index admission is not insignificant, reported as up to $18 \%$ in some studies (2). As such, there remains a lack of consensus regarding the timing of surgery, which requires further multi-institutional data to clarify.

There are limitations to the present study that must be considered when interpreting the results. Firstly, the patient cohort includes those who are under surveillance and have survived to the operating theatre, rather than all operative and non-operative type A IMH patients. Secondly, type A IMH is a relatively rare condition, and therefore this summary is based mostly on aggregation of small case series. The heterogeneity introduced by this reporting bias cannot be adequately controlled, particularly in the absence of larger multi-institutional studies. Thirdly, this review includes all surgical patients, including those who underwent initial emergency operation and those who had staged procedures. Conclusions regarding which approach is superior is beyond the scope of the present data. Finally, patient comorbidities and surgical approach cannot be standardized between studies due to the lack of presented 
information.

The present systematic review of surgical outcomes of type A IMH identified an acceptable risk of postoperative mortality. However, significant heterogeneity exists in outcomes for Western and Eastern centers. The lack of detailed data precludes further robust analysis of key clinical questions.

\section{Acknowledgments}

None.

\section{Footnote}

Conflicts of Interest: The authors have no conflicts of interest to declare.

\section{References}

1. Goldberg JB, Kim JB, Sundt TM. Current understandings and approach to the management of aortic intramural hematomas. Semin Thorac Cardiovasc Surg 2014;26:123-31.

2. Tittle SL, Lynch RJ, Cole PE, et al. Midterm follow-up of penetrating ulcer and intramural hematoma of the aorta. J Thorac Cardiovasc Surg 2002;123:1051-9.

3. (IHE). IoHE. Quality Appraisal of Case Series Studies Checklist. 2014.

4. Wan X, Wang W, Liu J, et al. Estimating the sample mean and standard deviation from the sample size, median, range and/or interquartile range. BMC Med Res Methodol 2014;14:135.

5. Guyot P, Ades AE, Ouwens MJ, et al. Enhanced secondary analysis of survival data: reconstructing the data from published Kaplan-Meier survival curves. BMC Med Res Methodol 2012;12:9.

6. Choi YJ, Son JW, Lee SH, et al. Treatment patterns and their outcomes of acute aortic intramural hematoma in real world: multicenter registry for aortic intramural hematoma. BMC Cardiovasc Disord 2014;14:103.

7. Evangelista A, Mukherjee D, Mehta RH, et al. Acute intramural hematoma of the aorta: a mystery in evolution. Circulation 2005;111:1063-70.

8. Ferrera C, Vilacosta I, Gómez-Polo JC, et al. Evolution and prognosis of intramural aortic hematoma. Insights from a midterm cohort study. Int J Cardiol 2017;249:410-3.

9. Hata M, Hata H, Sezai A, et al. Optimal treatment strategy for Type A acute aortic dissection with intramural hematoma. J Thorac Cardiovasc Surg 2014;147:307-11.

10. Kitai T, Kaji S, Yamamuro A, et al. Clinical outcomes of medical therapy and timely operation in initially diagnosed Type A aortic intramural hematoma: a 20-year experience. Circulation 2009;120:S292-8.

11. Liu G, Qin J, Cui C, et al. Endovascular repair of aortic arch intramural hematoma and penetrating ulcers with 810 $\mathrm{nm}$ in situ laser-assisted fenestration: Preliminary results of a single-center. Lasers Surg Med 2018;50:837-43.

12. Matsushita A, Fukui T, Tabata M, et al. Preoperative characteristics and surgical outcomes of acute intramural hematoma involving the ascending aorta: A propensity score-matched analysis. J Thorac Cardiovasc Surg 2016;151:351-8.

13. Moizumi Y, Komatsu T, Motoyoshi N, et al. Clinical features and long-term outcome of Type A and type B intramural hematoma of the aorta. J Thorac Cardiovasc Surg 2004;127:421-7.

14. Nakamura K, Onitsuka T, Yano M, et al. Clinical analysis of acute Type A intramural hematoma: comparison between two different pathophysiological types. Ann Thorac Surg 2006;81:1587-92.

15. Park KH, Lim C, Choi JH, et al. Prevalence of aortic intimal defect in surgically treated acute Type A intramural hematoma. Ann Thorac Surg 2008;86:1494-500.

16. Sandhu HK, Tanaka A, Charlton-Ouw KM, et al. Outcomes and management of Type A intramural hematoma. Ann Cardiothorac Surg 2016;5:317-27.

17. Schoenhoff FS, Zanchin C, Czerny M, et al. Aorta Related and All-cause Mortality in Patients with Aortic Intramural Haematoma. Eur J Vasc Endovasc Surg 2017;54:447-53.

18. Song JK, Yim JH, Ahn JM, et al. Outcomes of patients with acute Type A aortic intramural hematoma. Circulation 2009;120:2046-52.

19. Uchida K, Imoto K, Karube N, et al. Intramural haematoma should be referred to as thrombosed-Type Aortic dissection. Eur J Cardiothorac Surg 2013;44:366-9; discussion 369.

20. von Kodolitsch Y, Csosz SK, Koschyk DH, et al. Intramural hematoma of the aorta: predictors of progression to dissection and rupture. Circulation 2003;107:1158-63.

21. Maraj R, Rerkpattanapipat P, Jacobs LE, et al. Metaanalysis of 143 reported cases of aortic intramural hematoma. Am J Cardiol 2000;86:664-8.

22. Robbins RC, McManus RP, Mitchell RS, et al. Management of patients with intramural hematoma of the thoracic aorta. Circulation 1993;88:I11-10. 
23. Rozado J, Martin M, Pascual I, et al. Comparing American, European and Asian practice guidelines for aortic diseases. J Thorac Dis 2017;9:S551-60.

24. Hiratzka LF, Bakris GL, Beckman JA, et al. 2010 ACCF/AHA/AATS/ACR/ASA/SCA/SCAI/SIR/STS/ SVM guidelines for the diagnosis and management of patients with thoracic aortic disease. J Am Coll Cardiol 2010;55:e27-129.

25. Erbel R, Aboyans V, Boileau C, et al. 2014 ESC Guidelines on the diagnosis and treatment of aortic diseases: document covering acute and chronic aortic

Cite this article as: Tian DH, Chakos A, Hirst L, Chung STW, Yan TD. Surgery for type A intramural hematoma: a systematic review of clinical outcomes. Ann Cardiothorac Surg 2019;8(5):518-523. doi: 10.21037/acs.2019.08.07 diseases of the thoracic and abdominal aorta of the adult The Task Force for the Diagnosis and Treatment of Aortic Diseases of the European Society of Cardiology (ESC). Eur Heart J 2014;35:2873-926.

26. Group JJW. Guidelines for diagnosis and treatment of aortic aneurysm and aortic dissection (JCS 2011). Circ J 2013;77:789-828.

27. Zhou X, Krishnan A, Hsu J, et al. Delayed Surgical Management of Type A Intramural Hematoma Is Not Associated with Worse Outcomes Than Emergent Operation. Heart Surg Forum 2019;22:E103-6. 
Supplementary

Table S1 Modified quality assessment checklist, adapted from Quality Appraisal Tool for Case Series Studies published by Institute of Health Economics (Alberta, Canada)

Quality assessment checklist

1. Was the hypothesis/aim/objective of the study clearly stated?

2. Was the study conducted prospectively?

3. Were the cases collected in more than one centre?

4. Were patients recruited consecutively?

5. Were the characteristics of the patients included in the study described?

6. Were the eligibility criteria (i.e., inclusion and exclusion criteria) for entry into the study clearly stated?

7. Was the intervention of interest clearly described?

8. Were relevant outcome measures established a priori?

9. Were the relevant outcome measures made before and after the intervention?

10. Were the statistical tests used to assess the relevant outcomes appropriate?

11. Was follow-up long enough for important events and outcomes to occur?

12. Were losses to follow-up reported?

13. Were the adverse events reported?

14. Were the conclusions of the study supported by results?

15 . Were both competing interests and sources of support for the study reported? 